\title{
Coping with COVID-19 Prolonged and Cumulative Stressors: the Case Example of Egypt
}

\author{
Ibrahim A. Kira, ${ }^{1,2}$. Hanaa A. M. Shuwiekh ${ }^{3}$. Shereen Abd Elwahab Ahmed ${ }^{3}$. \\ Eman Ezzat Ebada ${ }^{3}$. Shireen Farouk Tantawy ${ }^{3} \cdot$ Nevein Nirouz Waheep $^{3}$. \\ Jeffrey S. Ashby ${ }^{4}$
}

Accepted: 9 November 2021

(c) The Author(s), under exclusive licence to Springer Science+Business Media, LLC, part of Springer Nature 2021

\begin{abstract}
The current study aimed to explore how COVID-19-traumatized populations cope using a coping model based on wills to exist, live, and survive (WTELS) that leads to positive coping and posttraumatic growth (PTG). We used data from 11 Arab countries $(N=2732)$, including Egypt $(N=831)$, and included measures for COVID-19 stressors (COVID-fear, economic, lockdown, and grief stressors), WTELS, resilience, religiosity, spirituality, social support, and PTG. We conducted ANOVA on the main sample to explore the differences between Arab countries, hierarchical regressions, and path analysis on the Egyptian subsample to test a model of the effects on WTELS. In the path model, WTELS was the independent variable. Other coping strategies were mediating variables, and COVID-19 stressor types were outcome variables. ANOVA on the main sample indicated that Egypt was the highest on COVID-19 stressors (infection fears, economic, lockdown, and grief stressors), actual infection, and WTELS. Hierarchical regression indicated that social support, resilience, and WTELS were positive predictors of PTG, with WTELS had the highest effect size $(\beta=.41)$ and WTELS being a negative predictor of COVID-19 stressors, while resilience and social support were not. Path analysis indicated that WTELS predicted higher religiosity, spirituality, social support, resilience, and lower COVID-19 stressors. Religiosity predicted higher spirituality, social support, and resilience and lower COVID19 stressors. Interfaith spirituality predicted higher resilience and lower COVID-19 grief stressors. The results validated the central role of WTELS. Results helped to identify potentially effective interventions with COVID-19 victims that focus on WTELS, spirituality, and religiosity.
\end{abstract}

Keywords COVID-19 stressors · Wills to exist, live, and survive $\cdot$ Religiosity $\cdot$ Resilience · PTG

The COVID-19 pandemic has had a profound global impact on health and well-being and has challenged and extended our understanding of traumatic stress (Kira, 2021a, b;

Ibrahim A. Kira

kiraaref@aol.com

Extended author information available on the last page of the article 
Kira et al. 2013b). There is an urgent and ongoing need to understand the psychological impact of COVID-19, its association with other traumas, and patterns of coping with these cumulative effects. One promising approach to examining these effects moves away from the traditional trauma paradigms that focus on past traumas and adopts a life-course perspective that includes attachment disruptions, discrimination, and continuous traumatic stressors, such as COVID-19 and coping with their global cumulative and proliferation dynamics (Kira, 2021).

Recent studies have found that COVID-19 stressors include at least four types of stressors that can amplify each other in cumulative dynamics (Kira et al., 2020d). They include COVID infection fears stressors, which erupt from reasonable and exaggerated fears of debilitating or mortal infection (for meta-analysis for the effects of COVID-19 fears, see: Şimşir et al., 2021). They include lockdown stressors, associated isolation, disrupted routines, and their social consequences such as increased domestic violence (e.g., Piquero et al., 2021; for meta-analysis, see: Prati \& Mancini, 2021). Also, they include economic stressors such as getting laid off, difficulty accessing resources, business loss, interrupted global trade and travel, and disruption in the global supply chain that crippled economies globally (e.g., Bazzoli et al., 2021; Yu et al., 2021), and grief stressors, i.e., angst for loss of loved one due to COVID infection ((Djelantik et al., 2021; Eisma et al., 2020).

COVID-19 traumatic stressors were found to impact mental health negatively (e.g., increased PTSD, depression, and anxiety) and executive function (Alpay et al. 2021; Kira et al., 2021a, b, for meta-analyses for its effects on mental health, see Cénat et al., 2020; Cooke et al., 2020; Luo et al., 2020; Marvaldi et al., 2021; Rogers et al., 2020; Salari et al., 2020; Salehi et al., 2021; Yuan et al., 2021). While the pandemic has affected the fabric of everyday life across the globe, most individuals have shown high levels of resilience (e.g., Pierce et al., 2021). The factors that predicted the worsening of mental health upon exposure to continuous traumatic stress, such as COVID-19, in different age groups, have been the focus of a considerable number of studies (e.g., Banerjee, 2020; De France et al., 2021; Gao et al., 2020; Holman et al., 2020). However, the factors that may contribute most to resilience have garnered much less attention. Coping with the multilayered and prolonged traumatic stress of the pandemic is a unique challenge. As a result, it may require the mobilization of innate strengths and the existential wills of the individuals to live and survive (WTELS) and the well-researched resilience, social support, religiosity, spirituality, and available material resources.

One of the regions where the mental health impact of COVID-19 attracted some attention is Arab countries (e.g., Abdelrahman et al., 2021; Saddik et al., 2021; Shuwiekh et al., 2020). As of October 2021, Egypt's Ministry of Health reported 312.000 infections and 17,658 deaths since the beginning of the pandemic (Egypt population is over 100 million) (https://graphics.reuters.com/world-coronavirus-tracker-and-maps/countries-and-terri tories/egypt/). Due to a variety of factors, COVID-19 is grossly under-reported in most Arab countries (e.g., Tuite et al., 2020a), and the results coming from samples drawn from the country, even convenience samples, may represent a more accurate approximation of the rates of infection and related stressors. Investigations of the psychological impacts of COVID-19 in Arab countries are generally limited to a single country. However, a recent study on the potential mental health impact of COVID-19 in seven Arab countries (Shuwiekh et al., 2020) found that the differences in COVID19 traumatic stress, PTSD, depression, and anxiety between the countries were significant and potentially caused, at least in part, by the differential status of populations' density and level of socioeconomic status. Post hoc analysis indicated that Egypt, the most populous and one among which have relatively lower income, is significantly higher in COVID-19 traumatic stress, PTSD, anxiety, and depression than all the other represented Arab countries. The subsamples from 
Palestine and Iraq had a significantly higher cumulative trauma load than the Egyptian subsample but did not have higher levels of COVID-19 traumatic stress. Analysis indicated that COVID-19 traumatic stressors accounted for significant variance above and beyond the variance accounted for by previous cumulative stressors and traumas in anxiety and PTSD, and depression in all countries (Shuwiekh et al., 2020).

In the current study, we want to verify the validity and stability of these findings, after 10 months of Shuwiekh et al.'s (2020) study, and use the Egyptians as a case example to explore how those highly traumatized by COVID-19 continuous and prolonged traumatic stressors may cope with such higher COVID-19 infection and COVID-19 traumatic stressors' load. That may help inform the strategies that treat and enhance the coping capacities of victims of COVID-19 traumatic stress syndrome in different countries and populations.

\section{Conceptual Framework}

Coping with COVID-19 involves an interrelated set of coping strategies that help survive and manage adversities and achieve real PTG. Such coping strategies include the persons' wills to survive, exist, live and win, resilience, religiosity, spirituality, and social support. Some of these coping trajectories overlapped. For example, religiosity includes increased social support by the religious community.

A one potentially useful framework for coping with unprecedented traumatic stress like the COVID-19 pandemic is the "will to exist, live, and survive" (WTELS). WTELS is the intrinsic, innate motivation to exist, live, survive, self-actualize, and thrive (Kira et al., 2020c, 2021f). Previous research found that the will to fight and survive is the source of most coping strategies (Kira et al., 2014c). WTELS is an existential feature that is a part of the person's agentic executive self (Kira et al., 2014b). While its vigor dynamics fluctuate, it is activated upon exposure to threats and adversities such as COVID-19. WTELS is best understood as a pre-cognitive and intrinsic executive capacity to access, master, mobilize, and optimize all available inner and external resources. Recent research (e.g., Kira et al., 2020a, c, 2021f) has found that WTELS has primacy over other critical coping strategies and is highly associated with resilience and PTG across different age groups and genders. These results suggest that WTELS, a non-cognitive (or pre-cognitive) factor, has positive consequences for cognitive, emotional, behavioral, and mental health.

WTELS is the intrinsic, innate motivation to exist, live, survive, self-actualize, and succeed/thrive (Kira et al., 2020b, p.48). WTELS is an existential feature that is a part of the person's agentic executive self (Kira et al., 2014b). Will or volition to exist is a precognitive process related to agency and executive action control (executive self) (Haggard, 2017). The will to survive (WTS), another essential part of WTELS, underlies different coping strategies to oppression (Kira et al., 2014a). Will to live (WTL) (Hutschnecker, 1951 ) is another essential dimension of WTELS. Bornet et al. (2020), in a review, found that WTL in the reviewed studies was positively associated with resilience $(r=0.63)$, life satisfaction $(r=0.55)$, happiness $(r=0.48)$, purpose in life $(r=0.42)$, quality of life $(r=0.51)$, and the presence of social contacts $(r=0.47)$. WTE, WTS, and WTL are proved to connect as powerful master motivation in the unidimensional construct of WTELS (Kira et al., 2020a). A recent study found that WTELS, as a meta-motivator, is highly predictive of executive function optimization and lowered psychopathology (Kira et al., 2021c).

Another quality that is generally viewed as a positive and significant factor in coping with adversities is resilience. Resilience is the healthy, adaptive, or integrated positive 
functioning overtime in the aftermath of adversity (Southwick et al., 2014). Individual resilience is based on the status of her/his developmental assets acquired life-course through development, including attachment styles and identity developmental assets (Benson et al., 2011; Darling Rasmussen et al., 2019; Kira, 2019). Resilience is one of the critical factors to positive mental health (for meta-analysis, see $\mathrm{Hu}$ et al., 2015; see also Färber \& Rosendahl, 2018; Oshio et al., 2018). COVID-19 challenged the impressive human capacity for resilience (e.g., Prime et al., 2020; Verdolini et al., 2021).

Another important coping strategy is seeking and exchanging social support. Social support is related to social and personal survival living in a network of social groups of belonging (e.g., Kroenke et al., 2006). The person's survival depends on a network of peers, friends, family, and different formal and informal, real and virtual groups. Social support has positive health outcomes (e.g., Barth et al., 2010; Miyazaki et al., 2003) and significantly affects well-being (for meta-analysis, see Vera et al., 2020).

For Muslims and Christians alike, other critical coping strategies, especially in most Arab cultures, are religiosity and spirituality (e.g., Kira \& Shwiekh, 2021; Vally et al., 2018). Religious coping is an effective coping strategy that leads to psychological adjustment to stress (for meta-analyses, see Ano \& Vasconcelles, 2005; Hackney \& Sanders, 2003). Religious and spiritual identities are salient in Middle Eastern cultures (Fischer et al., 2010).

While COVID-19 is prolonged severe trauma, it may yield significant posttraumatic growth (PTG). A study across 78 countries indicated that $40 \%$ of the respondent reported high levels of psychological flourishing despite the pandemic, and only $10 \%$ reported the highest level of mental health difficulties (Gloster et al., 2020, see also Ikizer et al., 2021). PTG in Arabic countries and especially in Egypt, the highest Arab country affected, is rarely examined.

Demographics (income, age, gender, education) are essential factors in understanding the effectiveness of COVID-19 coping responses. Demographics appear to interact with trauma factors to influence whether individuals adopt more or less adaptive coping responses to the pandemic (Volk et al., 2021). For example, gender may affect the choice of coping strategy and modify or modulate the coping response (Eschenbeck et al., 2007). Earlier research found that females tend to appraise events as more stressful than males (Barbosa-Leiker et al., 2013) and present higher depression as a response to stressors (for meta-analysis, see Shanmugasegaram et al., 2012). Another example is higher SES (and income). There are replicated evidence that SES is a significant protective factor for the impact of the stressors (for meta-analyses, see Lorant et al., 2003; Peverill et al., 2020). While educational attainment is usually a protective factor (e.g., Erickson et al., 2016), the COVID-19 stressors' disruption of the education system (e.g., McGinty et al., 2020) can affect the mediating role of education, as education may represent additional stressors in COVID-19 environment especially for college students. Also, the threat of COVID-19 to older people (e.g., Le Couteur et al., 2020) may make old age a risk factor for COVID-19 stressors.

The first goal of the current study is to verify, in a second round of data collection, previous findings of Egypt's high COVID-19 infection and COVID-19 stressors compared to other Arab countries after 10 months through COVID. The second goal is to explore the coping strategies that those most affected Egyptians use to adapt to COVID19 infection and stressors. For this purpose, We will test a conceptual model of coping with COVID-19 stressors in which WTELS motivates resilience, spirituality and religiosity, and social support to produce PTG in a highly infected and affected Arab country. 


\section{Hypotheses}

Hypothesis 1: Egyptians are higher in COVID-19 infection and COVID-19 four traumatic stressors types than other Arab countries, replicating previous findings 10 months ago.

Hypothesis 2: WTELS, social support, resilience, and COVID-19 stressors are positive predictors of PTG. Based on the results of previous studies reviewed on WTELS, WTELS will have the largest effect size predicting PTG.

Hypothesis 3: Female gender, higher education, and older age are predictive of higher COVID-19 cumulative stressors, while high yearly income is a negative predictor for higher COVID-19 cumulative stressors.

Hypothesis 4: COVID-19 cumulative stressors, as traumatic stressors, are significantly associated with higher PTG.

Hypothesis 5a: WTELS is a strong negative predictor of COVID-19 cumulative stressors.

Hypothesis 5b: WTELS is associated with increased religiosity, resilience, social support, and spirituality and reduced COVID-19 stressors in the Egyptian subsample.

\section{Methods}

\section{Participants}

The sample included $N=2732$ adults from 11 Arab countries (Algeria, Iraq, Jordan, Kuwait, Lebanon, Libya, Palestinian, Saudi Arabia, Sudan, UAE, and Egypt). Age ranged from 18 to 91 , mean $=26.92$, and $\mathrm{SD}=10.01$ with $69.3 \%$ females. For religion, $97.3 \%$ were Muslims and 1.4\% Christians, $0.3 \%$ Jewish, and $1 \%$ other. For education, $1.4 \%$ had reading and writing level, $8.7 \%$ high school level, $81.6 \%$ college level, and $8.3 \%$ graduate studies level. For marital status, $63.2 \%$ were single, $31 . \%$ married, $3.2 \%$ widowed, and $0.9 \%$ divorced. For employment, $27.2 \%$ were working with the government, $58.1 \%$ students, $6.2 \%$ private business, $2.2 \%$ retired, and $5.8 \%$ unemployed. For socioeconomic status, $0.7 \%$ of the participants reported very low, $1.2 \%$ low, $81.3 \%$ in the middle, $14.5 \%$ high, and $2.3 \%$ very high. For the countries that were represented in the sample, $30.4 \%$ were from Egypt $(N=831)$.

For the Egyptian sub-sample $(N=831)$, the focus of the current study, $63.9 \%$, were females. Age ranged between 17 and $71(\mathrm{M}=32.61, \mathrm{SD}=12.01)$. For work, $38 \%$ are students, $32.6 \%$ are government employees, $10.23 \%$ private work, $4.7 \%$ retired, and $14.4 \%$ unemployed. For marital status, $49.1 \%$ are married, $45.4 \%$ single, $1.7 \%$ widowed, and $2.8 \%$ were divorced. For socioeconomic status (SES), $0.6 \%$ report very low SES, $1.8 \%$ low SRS, $97 \%$ middle SES, and $0.6 \%$ very high SES. For education, $0.4 \%$ have good reading and writing abilities, $11.1 \%$ have high school-level education, $69.6 \%$ have college-level education, and $19 \%$ have graduate-level education. For religion, $95.5 \%$ were Muslims, $4.1 \%$ were Christians, and $0.4 \%$ were Jewish. 


\section{Procedures}

The field study teams included graduate students in each of the targeted Arab countries that collected the data under supervision of their advisors. They administered the questionnaires to participants from December 2020 to March 2021. We chose the eleven Arabic countries: Algeria, Iraq, Jordan, Kuwait, Lebanon, Libya, Palestine, Saudi Arabia, Sudan, UAE, and Egypt, to represent the 22 Arab countries (50\%). We used Google Drive and developed a survey link. Once the participant completed the survey, it was sent anonymously to Gmail. The questionnaire In Egypt was administered face to face $=17.5 \%$, and online $=82.5 \%$, while the administration in the other Arab countries was $100 \%$ online. Participation was voluntary with built-in informed consent; each person took approximately 20-30 min to complete the entire questionnaire. The sponsoring university Institutional Review Board (IRB) approved the research protocol as part of a cross-cultural study of the impact of COVID-19.

\section{Measures}

\section{COVID-19 Cumulative Stressors Scale}

The scale was developed in two studies (Kira et al., 2020d, 2021d, Kira et al., 2021d, kira et al., 2021e) and showed good construct convergent-divergent and predictive validity. It is a 17-item scale including four subscales (1) "threat/fear of the present and future infection and death" (5 items), (2) "traumatic economic stress" (4 items), (3) "isolation and disturbed routines" (3 items), and (4) traumatic grief stressors (4 items). Items are scored on 5-point scale, with (1) indicating not at all and (5) very much. Examples of items include, "How concerned are you that you will be infected with the coronavirus?" "The Coronavirus (COVID-19) has impacted me negatively from a financial point of view." "Over the past two weeks, I have felt socially isolated as a result of the coronavirus." In the current study, the scale had an alpha of 0.88. Its four subscales had Cronbach alpha of $0.91,0.75,0.76$, and 0.72 , respectively.

\section{The "Will to Exist, Live, and Survive" (WTELS) Scale (Kira et al., 2020a, c)}

WTELS scale is a 6-item scale that measures different aspects of will to exist, live, survive, and thrive. It includes items such as "I am motivated by a drive to live"; "My will to exist and survive adversity is generally high." We scored each item on a 5-point scale: $4=$ very strong, $3=$ strong, $2=$ neutral, $1=$ drained/depleted, and $0=$ extremely depleted $/ \mathrm{I}$ have no will to survive. Exploratory and confirmatory factor analyses found that the measure has a one-factor structure. The measure's one-factor structure was strictly invariant across gender, cultural, and religious groups. We should clarify that the WTELS scale is a short parsimonious measure, which did not allow robust testing of the three distinct unique components structure. WTELS construct is comprised of three distinct but overlapping components. A three-factor model was not established or tested because it was a short instrument consisting of only six items (a longer test allows at least four items per dimension). The study also found that the measure's test-retest stability coefficient (4 weeks interval) on a sample $(N=34)$ was 0.82 . WTELS has good convergent, divergent, and 
predictive validity. WTELS predicted a decrease in existential anxiety and mental health symptoms, and increased emotion regulation (reappraisal), self-esteem, and posttraumatic growth (Kira et al., 2020b). The Cronbach's reliability of the scale in current data is. 91 .

\section{Connor-Davidson Resilience Scale (CD-RISC) 10-Item Version (Campbell-Sills \& Stein, 2007; Connor \& Davidson, 2003)}

The participant rates each item on a 5-point scale, with responses from not true at all (0) to true nearly all times (4). The total score ranges from $0-50$. The original measure showed adequate internal consistency, test-retest reliability, and convergent and divergent validity (Connor \& Davidson, 2003). The short version CD-RISC-10 showed the same original version's psychometrics (Scali et al., 2012). In our sample, the CD-RISC-10 showed adequate internal consistency (Cronbach's $\alpha=0.81$ ).

Social Support Survey (Sherbourne \& Stewart, 1991) is a 12-item scale. It consists of emotional/informational support (8 items) and tangible support (4 items) subscales. The participant rates each item on a 5-point scale, with (1) means none of the time and (5) indicates all of the time. Multitrait scaling analyses found four functional support dimensions: emotional/informational, tangible, affectionate, and positive social interaction. The measure proved to have good reliability and to be reasonably stable over time (Sherbourne, $\&$ Stewart, 1991). It has $\alpha=0.92$ in the current study.

The Posttraumatic Growth Inventory (PTGI; Tedeschi \& Calhoun, 1996) assesses perceived positive life changes (e.g., enhanced relationships, greater life appreciation) following stressful experiences. In completing the 21 items, participants respond on a scale from 0 (I did not experience this change as a result of my experience) to 5 (I experienced this change to a very significant degree). The measure includes five subscales designed to measure the following: relating to others, new possibilities, personal strength, spiritual change, and appreciation of life. In a validation study, Tedeschi and Calhoun (1996) found the internal consistency of the total PTGI to be 0.90 and the test-retest reliability to be 0.71 . The measure also appears to have sound psychometric properties in the Arabic language version (Kira et al., 2012, 2013a), with an $\alpha$ of 0.96 for the primary measure. In the current data, the scale had an $\alpha$ of 0.90 . Alpha coefficients ranged between 0.83 and 0.70 for its five subscales.

\section{Interfaith Spirituality Scale Short form (IFS-S) (4 items) (Kira et al., 2019)}

The measure initially consisted of four components: asceticism, close relationship with the creator, divine love, and meditation. The subject was asked to specify if each statement is true for him/her on a scale from 1 to 4 , with (4) mostly true about me and (1) not true about me. The instruction presented a detailed description of spirituality as "the feeling of a direct relation with your maker, and your ability to transcend yourself." With "Creator" indicates "the force that sets totality into existence, as you understand it." The scale showed good convergent, divergent, predictive, and structural validity, good internal consistency, and stability. In current data, it has an alpha of 0.97 .

Religiosity Scale is five items used previously with similar populations (e.g., Kira et al., 2006). It consists of items that assess the constant observance of religion. It also consists of items about congregating with persons from the same faith, reading their faith's scripture, and contributing to charities. In current data, the scale has an alpha of 70. 


\section{Demographic Variables}

In addition to the independent and outcome variables measured, demographic information was collected and included age, gender, marital status, education, religion, and income. Yearly income was assessed on a score from 1 to 5, according to the reported income.

\section{Data Analysis}

We used IBM-SPSS 22 and Amos 22 software to analyze the data. The inspection of the variables indicated that there are no missing values in the data. The survey was set up as it was not possible to proceed without entering a response. We conducted zero-order correlations between the main variables. In addition to descriptives and correlations, we conducted an analysis of variance (ANOVA) to test the differences between the 11 Arab countries in COVID-19 stressors and in the will to exist, live, and survive. Additionally, we conducted hierarchical multiple regression to test two models for the effects of WTELS, resilience, spirituality, social support, and religiosity on PTG, and the effects of WTELS and the other related coping strategies on COVID-19 stressors. We recoded the categorical variables into dummy variables. We tested for collinearity between variables and if the variance inflation factor (VIF) is less than 5.00 for all the models (e.g., Hair et al., 2017). Further, to test the model of the effects of WTELS on COVID-19 traumatic stressors as mediated by resilience, religiosity, and interfaith spirituality on the Egyptian sample, we conducted a mediated path analysis. The path model included WTELS as independent variable and resilience, religiosity, spirituality, and social support as mediating variables, and COVID-19 four stressor types as outcome variables. We reported direct, indirect, and total effects as standardized regression coefficients. We computed the indirect to total effect ratio as an indicator of the mediator's amount of variance. We used a bootstrapping procedure with 10,000 bootstrap samples to examine the significance of direct, indirect (mediated effects), and total effects and $95 \%$ bias-corrected confidence intervals for each variable in the model. To simplify the presentation, we trimmed the model by eliminating the nonsignificant paths. Further, we tested alternative models to explore potentially better fitted or equally fitted models. We used Byrne's (2012) recommendations for the path model for the acceptable fit criteria. The criteria for good model fit were a non-significant chi-square $\left(\chi^{2}\right)$, chi-square/degrees of freedom $\left(\chi^{2} / \mathrm{df}>5\right)$, comparative fit index (CFI) values $>0.90$, and root-mean-square error of approximation (RMSEA) values $<0.06$ (Weston \& Gore, 2006).

\section{Results}

\section{Descriptives}

A total of $15.6 \%$ reported having been diagnosed at a certain point to have COVID-19, which $5.3 \%$ have been hospitalized for COVID-19 severe symptoms. There is a significant difference between Arab countries in COVID infection and hospitalization rates, with Egypt seems to have the highest level of hospitalization (Fig. 1). 


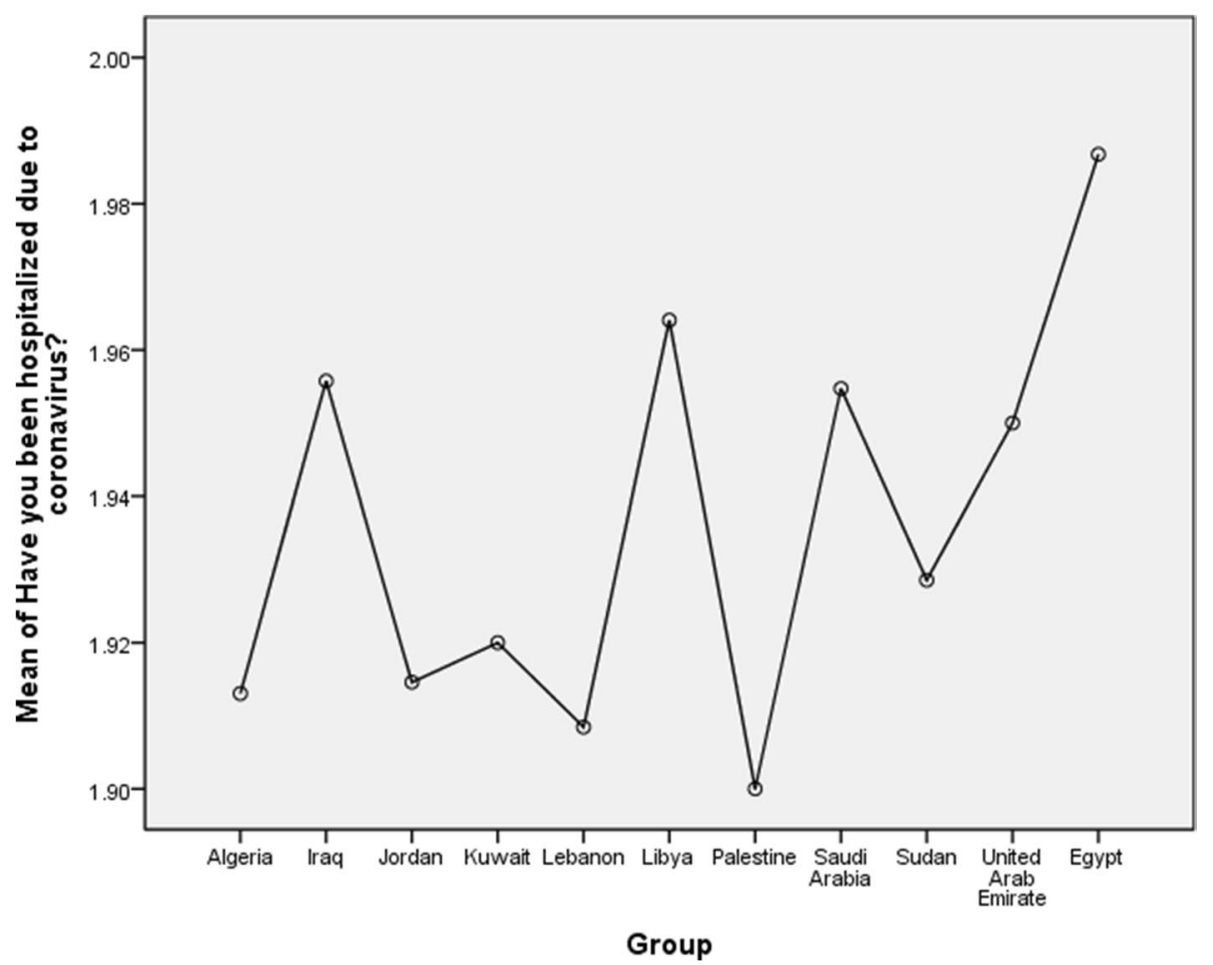

Fig. 1 The level of hospitalization due to COVID-19 infection in Arab countries in the sample

\section{ANOVA Results}

A one-way ANOVA of the differences between Arab countries was conducted to compare the differential effects of COVID-19 traumatic stressors (and their four types) on different Arab countries. There was a significant differential effect s of COVID-19 traumatic stressors on different Arab countries at the $p<0.000[F=(10,2721) 20.247$, $p=0.000]$. Post hoc comparisons using the Bonferroni test indicated that the mean score for the COVID-19 traumatic stressors was not significantly different in each of the 11 Arab countries sampled, except for Egypt. Egypt's score was significantly higher (see Fig. S-5 in supplemental materials).

Concerning the differential effects of COVID-19 infection fears stressors, there was a significant differential effect of COVID-19 infection fears on different Arab countries at the $p<0.000[F=(10,2721) 25.611, p=0.000]$. Post hoc comparisons using the Bonferroni test indicated that the mean score for the COVID-19 traumatic stressors was not significantly different in each of the 11 Arab countries sampled, except for Egypt. Egypt's score was significantly higher (see Fig. 1-S in supplemental materials).

Concerning the effects of COVID-19 economic stressors, there were significant differential effects of COVID-19 infection fears on different Arab countries at the $p<0.000$ $[F=(10,2721) 12.61, p=0.000]$. Post hoc comparisons using the Bonferroni test indicated that the mean score for the COVID-19 traumatic stressors was not significantly 
different in each of the 11 Arab countries sampled, except Egypt and Sudan, with higher economic stressors for each (see Fig. 2-S in supplemental materials).

Concerning the effects of COVID-19 grief stressors, there was a significant differential effect of COVID-19 infection fears on different Arab countries at the $p<0.000$ $[F=(10,2721) 8.593, p=0.000]$. Post hoc comparisons using the Bonferroni test indicated that the mean score for the COVID-19 traumatic stressors was significantly different in most of the 11 Arab countries sampled, except Egypt and Sudan, which were similar and significantly higher (see Fig. 3-S in supplemental materials).

Concerning the effects of COVID-19 lockdown stressors, there was a significant differential effect of COVID-19 lockdown stressors on different Arab Countries at the $p<0.000[\mathrm{~F}=(10,2721) 3.150, p=0.001]$. Post hoc comparisons using the Bonferroni test indicated that the mean scores for the COVID-19 traumatic stressors were not significantly different in most of the 11 Arab countries sampled, except Egypt and Algeria and Egypt and UAE. Lockdown stressors were significantly higher in Egypt than Algeria and UAE (see Fig. 4-S in supplemental materials).

For WTELS, there were significant differential effects of WTELS in different Arab countries. Post hoc comparisons (Bonferroni test) indicated that mean scores for WTELS were significantly different in most Arab countries, with Egypt has the highest mean for WTELS followed by Libya and Palestine (see Fig. S-6 in supplemental materials).

\section{Hierarchical Multiple Regression Results}

The first model examined the effects of demographics, resilience, social support, WTELS, and COVID-19 cumulative stressors on PTG. In the first step, age and education were significant positive predictors of PTG, while yearly income was a negative predictor of PTG. All demographics lost their significance in the second step when entered resilience, social support, WTELS, and COVID-19 cumulative stressors. Social support, resilience, COVID-19 stressors, and WTELS were positive predictors of PTG with WTELS had the highest effect size $(\beta=0.41)$, followed by resilience $(\beta=0.19)$, and COVID-19 cumulative stressor $(\beta=0.17)$, and social support $(\beta=0.08)$. The model accounted for 0.354 of the variance. Table 1 details these results.

In the second model, we examined the effects of demographics, resilience, social support, WTELS, and PTG on COVID-19 cumulative stressors. In the first step, gender, education, and age were predictive for higher COVID-19 cumulative stressors, while yearly income was a negative predictor. In the second step, we entered social support and PTG. Social support was a negative predictor, while PTG was a positive predictor of COVID-19 cumulative stressors. In the third step, we added WTELS. WTELS was a strong negative predictor of COVID-19 cumulative stressors $(\beta=-0.16)$, while resilience or social support was not a significant predictor of lower COVID-19 stressors. PTG continued to be significantly associated with higher COVID-19 cumulative stressors. Gender female, old age, and education were significant positive predictors, while higher income was a negative predictor of COVID-19 cumulative stressors, and these demographics remained significant in all three steps. The model accounted for only 0.071 of the variance, which means other significant predictors of cumulative COVID19 stressors were not included in the equation, such as behavior and personality factors. Table 2 presents these results. 
Table 1 Hierarchical multiple regression for the effects of resilience, social support, and WTELS and COVID-19 traumatic stress on posttraumatic growth

\begin{tabular}{|c|c|c|c|c|c|c|c|c|}
\hline \multirow[t]{2}{*}{ Predictor } & \multicolumn{4}{|l|}{ Step 1} & \multicolumn{4}{|l|}{ Step 2} \\
\hline & $B(S E)$ & $t$ & $\beta$ & $V I F$ & $B(S E)$ & $t$ & $\beta$ & $V I F$ \\
\hline Gender & $0.49(0.56)$ & 0.88 & 0.02 & 1.034 & $0.48(0.46)$ & 1.05 & 0.02 & 1.034 \\
\hline Age & $0.16(0.03)$ & 5.83 & $0.12 * * *$ & 1.132 & $0.01(0.02)$ & 0.49 & 0.01 & 1.132 \\
\hline Marital status & $-0.52(0.37)$ & -1.41 & -0.03 & 1.104 & $-0.05(0.30)$ & -0.18 & -0.00 & 1.104 \\
\hline Yearly income & $-1.08(0.51)$ & -2.12 & $-0.04 *$ & 1.012 & $-0.43(0.42)$ & -1.02 & -0.02 & 1.012 \\
\hline Education & $1.60(0.54)$ & 2.96 & $0.06^{* *}$ & 1.019 & $-0.04(0.46)$ & -0.09 & -0.00 & 1.019 \\
\hline Resilience & & & & & $0.32(0.03)$ & 10.46 & $0.19 * * *$ & 1.042 \\
\hline Social_Support & & & & & $0.09(0.02)$ & 4.45 & $0.08 * * *$ & 1.193 \\
\hline WTELS & & & & & $0.76(0.03)$ & 21.46 & $0.41 * * *$ & 1.111 \\
\hline $\begin{array}{l}\text { COVID-19 } \\
\text { cumulative } \\
\text { stressors }\end{array}$ & & & & & $0.20(0.02)$ & 10.98 & $0.17 * * *$ & 1.020 \\
\hline$R^{2}$ & 0.021 & & & & 0.354 & & & \\
\hline $\mathrm{R}^{2}$ change & 0.021 & & & & 0.323 & & & \\
\hline$F$ for $R^{2}$ change & $11.83^{* * *}$ & & & & $0.334 .94 * * *$ & & & \\
\hline
\end{tabular}

Note: $* p<0.05$. $* * p<0.01 . * * * p<0.001$ (two-tailed)

\section{Path Analysis Results}

In the model, WTELS had direct effects on religiosity $(b=0.26, p<0.01)$ and direct negative effects on COVID-19 economic stressors $(b=-0.26, \mathrm{p}<0.01)$. It has direct $(b=0.31$, $p<0.01)$ and indirect $(b=0.07, p<0.01)$ effects on spirituality, direct $(b=0.29, p<0.05)$ and indirect effects $(b=0.02, p<0.01)$ on social support, and direct $(b=0.23, p<0.01)$ and indirect effects $(b=0.03, p<0.05)$ on resilience. It had direct $(b=.-0.09, p<0.10)$ and indirect negative effects $(b=-0.15, p<0.01)$ on COVID-19 lockdown, direct $(b=-0.08$, $p<0.01)$ and indirect $(b=-0.12, p<0.01)$ on COVID-19 grief stressors, and indirect negative effects $(b=-0.16, p<0.01)$ on COVID-19 fear stressors. Its direct effects on spirituality were $82 \%$ of its total effects. Its direct effects on resilience were $89 \%$ of its total effects. Its direct effects on social support were $84 \%$ of its total effects. WTELS's indirect effects on lockdown stressors were $63 \%$ of its total effects. Its indirect effects on COVID19 grief stressors were $60 \%$ of its total effects.

Religiosity had direct effects on interfaith spirituality $(b=0.28, p<0.01)$ and social support $(b=0.09, p<0.01)$. It had indirect effects on resilience $(b=0.02, p<0.05)$. It had direct $(b=-0.12, p<0.05)$ and indirect negative effects $(b=-0.01, p<0.05)$ on COVID19 fear stressors and indirect negative effects on COVID-19 grief $(b=-0.06, p<0.01)$ and lockdown stressors $(b=-0.05, p<0.01)$. Its direct negative effects on COVID-19 fear stressors were $92 \%$ of its total effects. Interfaith spirituality had direct effects on resilience $(b=0.08, p<0.05)$ and indirect negative small but significant effects on COVID-19 fear $(b=-0.01, p<0.05)$, lockdown $(b=-0.01, p<0.05)$, and grief stressors $(b=-0.01$, $p<0.05)$.

Resilience had direct negative effects on COVID-19 fear stressors $(b=.-13, p<0.001)$ and indirect negative effects on lockdown $(b=-0.06, p<0.001)$ and grief stressors $(b=-0.06, p<0.001)$. COVID-19 economic stressors had direct effects on COVID-19 fear 


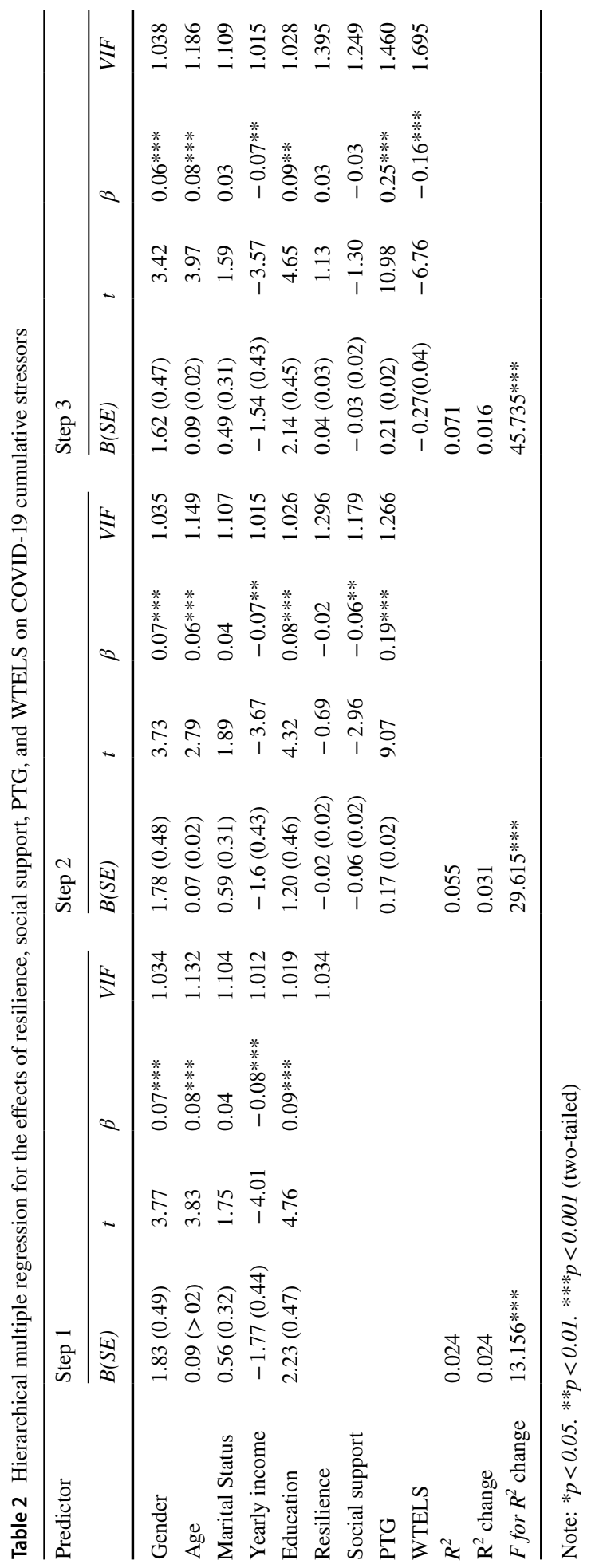


stressors $(b=0.35, p<0.01)$, direct effects $(b=0.31, p<0.01)$ and indirect effects $(b=0.15$, $p<0.001)$ on lockdown stressors, and indirect effects $(b=0.26, p<0.001)$ on COVID19 grief stressors. Their direct effects on lockdown accounted for $67 \%$ of its total effects. COVID-19 infection fears stressors had direct effects on lockdown stressors $(b=0.42$, $p<0.001)$ and direct $(b=0.37, p<0.001)$ and indirect $(b=0.12, p<0.001)$ effects COVID19 grief stressors. Their direct effects on lockdown stressors accounted for $76 \%$ of its total effects. COVID-19 lockdown stressors had direct effects on grief stressors $(b=0.29$, $p<0.01)$. Lockdown stressors accounted for the highest variance in the model $\left(R^{2}=0.407\right)$, followed by COVID-19 grief $\left(R^{2}=0.355\right)$. Figure 2 presents the direct standardized paths between the variables, while Table 3 provides the standardized path coefficients of the direct, indirect, and total effects and their $95 \%$ confidence intervals.

\section{Alternative Models Results}

We tested four alternative models putting the independent variable to be either religiosity, resilience, interfaith spirituality, or social support, to compare them with WTELS as the independent variable. All the alternative models fitted the data well and have almost equal fit with the chosen model (Figs. S5-S8 in supplemental materials). However, the standardized effect size of WTELS on lower COVID-19 different stressors and the number of its significant paths to them was much higher than those in all the tested alternative models.

\section{Discussion}

The current study conducted 10 months after the first study replicated the first study findings that Egypt has higher infection rates and higher COVID-19 stressors than other Arab countries. However, in both studies, Egyptians have higher wills to exist, live, and
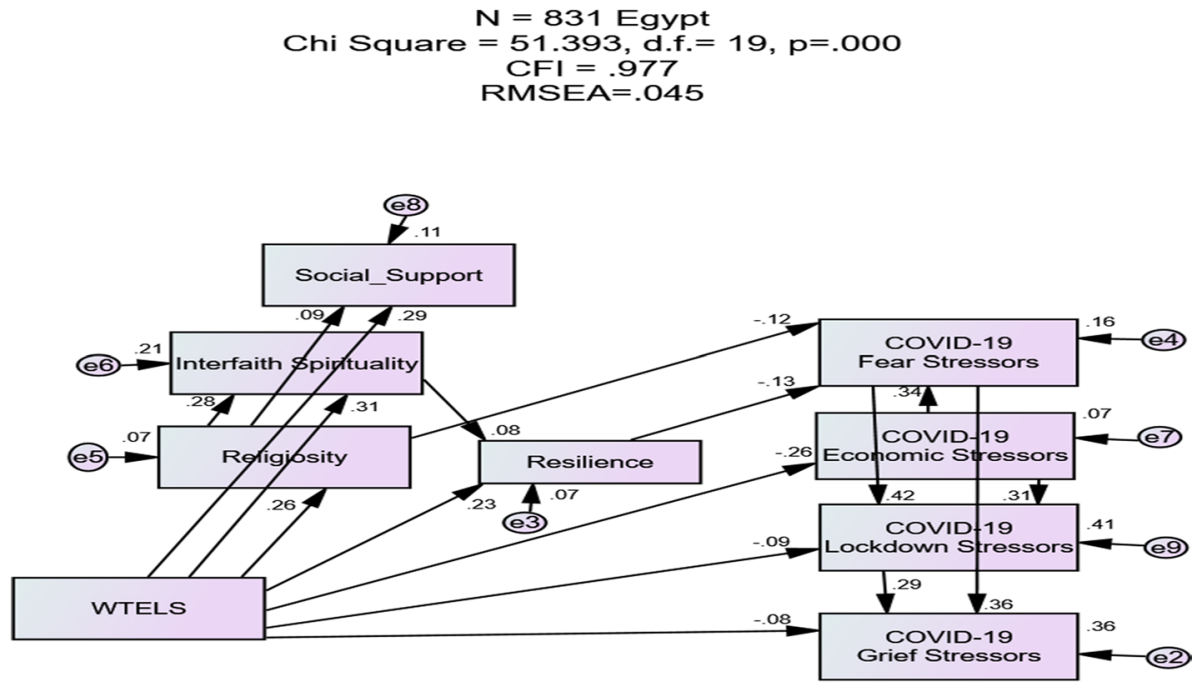

Fig. 2 Path analysis for the direct effects of WTELS (the main independent variable), religiosity, and spirituality on resilience and COVID-19 four stressor types 


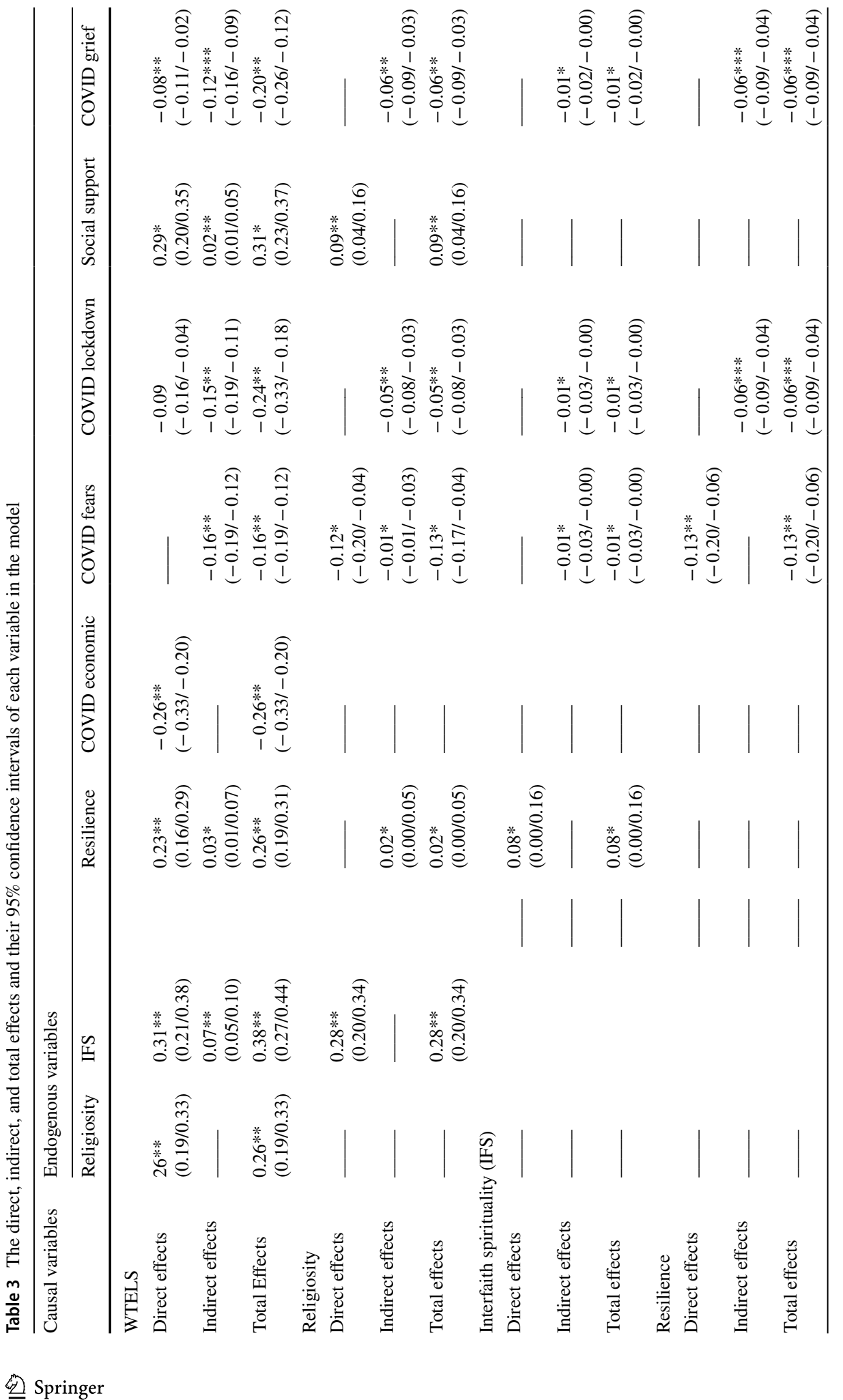




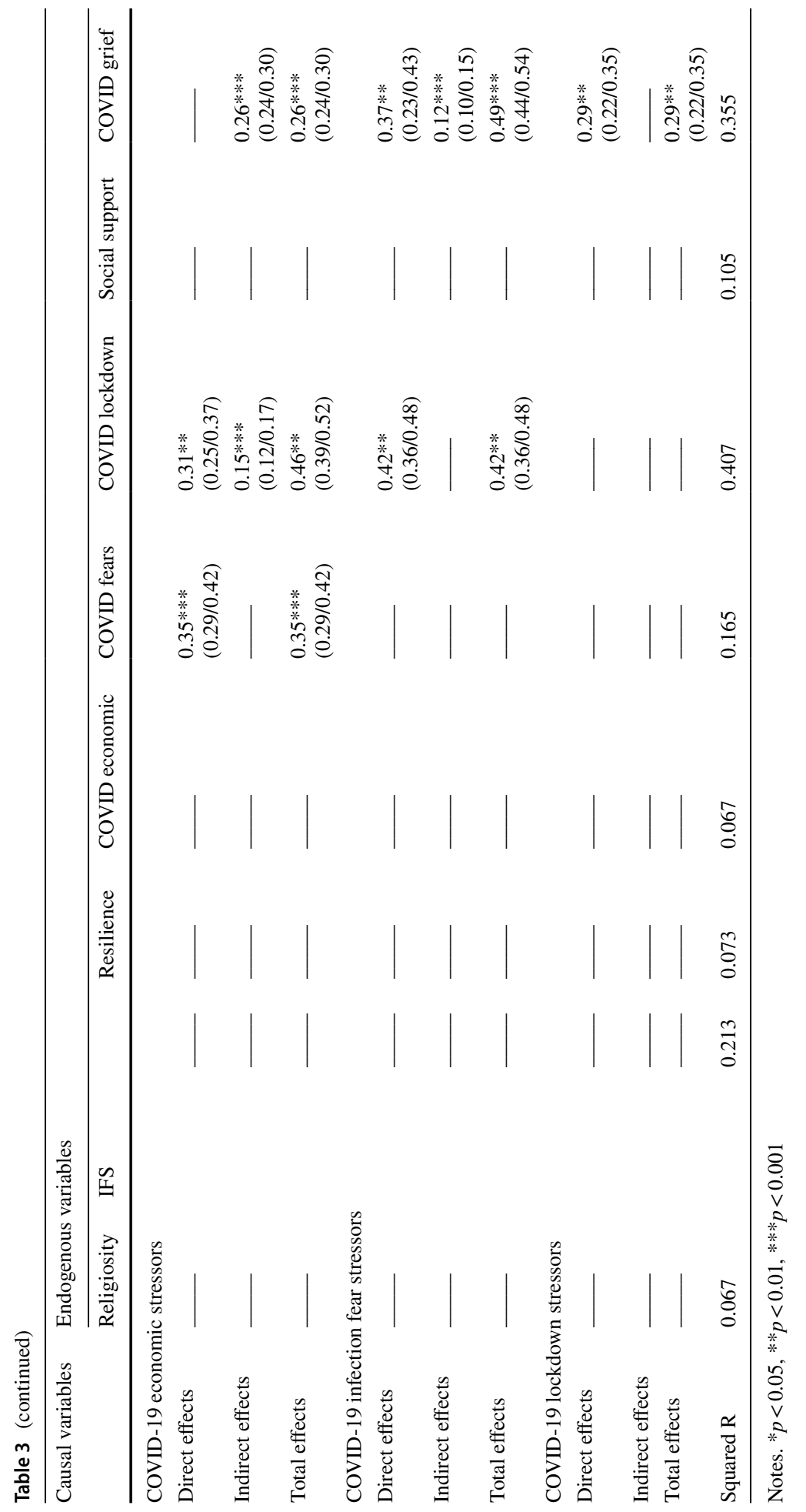


survive, which helped them cope and triggered their resilience and religiosity, interfaith spirituality, and social support that predicted their PTG. Egyptians' wills are central to their coping with the pandemic and stimulating posttraumatic growth. The results also found that gender female, higher education, and older age are predictive of higher COVID-19 stressors, while higher-income was predictive of lower COVID-19 stressors. The same demographics were not significant predictors of post-COVID-19 wills, related coping strategies, or PTG. The higher threat of COVID-19 to older persons (e.g., Le Couteur et al., 2020) made the elders more stressed about COVID-19. Females are more sensitive to stressors in general (e.g., Barbosa-Leiker et al., 2013). Highly educated may have higher awareness and be more sensitive to COVID-19 stressors. COVID-19 stressors' disruption of the education system presented additional stressors in the COVID-19 context, especially for college students (e.g., McGinty et al., 2020). High income and SES, in general, is a well-established protective factor of stress (Peverill et al., 2020). The results validated the third hypothesis of the study.

While Egyptians are higher in COVID-19 infection and on COVID-19 cumulative stressors than other Arab countries, their WTELS is higher, which may help them cope with such high amplitude stressors. Is the high WTELS due to the higher challenges of COVID-19 stressors, or is it the case for Egyptian participants? This question should be answered in future research. The Egyptian case provides an example of how populations cope with COVID-19 stressors. WTELS nurtures resilience, religiosity, spirituality, and social support and directly and indirectly significantly influences COVID-19 stressors reduction. Future studies need to replicate the findings of the current study about coping with such stressors. However, the fact that different alternative models fitted, as well, gave us the option to consider these different alternative models that may fit better in different populations. At the same time, WTELS had a larger standardized effect size and more significant paths associated with COVID-19 stressors' reduction.

In the Egyptian case, religiosity (and interfaith spirituality) was a strong predictor of COVID-19 stressors reduction, especially for COVID-fear stressors. Religiosity and spirituality are salient factors in coping for Egyptian Muslims and Christians alike (Kira \& Shuwiekh, 2021). The study may be the first to emphasize the role of "wills" (WTELS) in coping and provide empirical evidence of their primacy dealing with high amplitude traumas ( see also, Bornet et al., 2020; Kira et al., 2020a, b, 2021f).

Social support had the slightest effect size (association) with reducing COVID-19 stressors, which may be understandable in the lockdown environment with less social and physical interaction. Giving support to others positively influences the health of the individual receiving support and the individual who is giving the support. Increased support-giving was found to be associated with a reduction in amygdala reactivity in the sympathetic nervous system (SNS), hypothalamic-pituitary-adrenal (HPA) axis, and related inflammatory responding (e.g., Inagaki, 2018).

The current study has several conceptual and clinical implications. Conceptually, it emphasized that coping with such unprecedented traumatic stress requires the intrinsic natural "wills to exist, live, and survive" to load, mobilize, and optimize all available inner capacities and external resources. WTELS had a larger standardized effect size and more significant paths associated with COVID-19 stressors' reduction. It had significant effects on resilience, religiosity, social support, and spirituality, which is generally consistent with previous findings discussed in the introduction and reviewed by Bornet et al. (2020). Resilience in the context of continuous prolonged severe stressors is an ecological phenomenon in which the individual's WTELS is an integral part of its formula of coping with continuous traumatic stress (e.g., Nuttman-Shwartz \& Green, 
2020). Furthermore, WTELS was found to optimize executive functions (Kira et al., 2021c).

Clinically, current study results indicated that a critical focus of the prevention and intervention with COVID-19 victims (and other victims of other types of CTS or type III traumas) is to prime and optimize their intrinsic natural wills as it is one of the keys to effective coping with such extreme traumas. Our study provided evidence that WTELS is a key that may release a chain reaction cascade of effective coping strategies, resilience, religiosity, spirituality, and social support, significantly reducing COVID-19 traumatic stress. Using motivational interviewing techniques to stimulate the salience of these intrinsic "wills" as the master motivator may be helpful. Also, some clinicians proposed the model of "current, continuous, and cumulative trauma-focus cognitive behavior therapy" (Kira et al., 2015), which is relevant to COVID-19 continuous multilayered traumatic stressors.

One of the limitations of the current study is that it was conducted on convenient samples with limited and biased representation toward the female gender. We recommend more studies that use representative samples. Another limitation is that the measures we used were based on participants' self-reports. Self-reports are subject to under- or over-reporting due to social desirability. Furthermore, when we talk about direct and indirect effects, we must caution that statistical probabilistic stochastic terms used in path analysis do not mean the same thing in deterministic sciences of cause and effect. However, the study constitutes a significant contribution to understanding some of the dynamics of effective coping with severe prolonged cumulative stressors, such as those of COVID-19, giving Egypt as a case example. Future research is especially needed to replicate and explore more potential coping strategies to severe, prolonged, and cumulative stressors.

Supplementary Information The online version contains supplementary material available at https://doi. org/10.1007/s11469-021-00712-x.

Acknowledgements The authors are grateful to Engineers and graduate students: Idris Badie from Libya, Fahd Jalal from Iraq, Ruslan Uday from Saudi Arabia, Agwad Badawy from Jordan, Arshad Basil from Palestinian, Naji Ghatawan from Lebanon, Hamza Ayyash from Emirates, Bilal Hajj from Algeria, and Said Aaron from Sudan, for their superb leadership in the data collection procedure from their respective countries. Further we are grateful for Dr. Alaa Mohamed Mahmoud Eliwa and Dr. Sayed Ahmad Elwkeel for helping in data collection in Egypt.

Data Availability The datasets generated during and/or analyzed during the current study are available from the corresponding author on reasonable request.

\section{Declarations}

Ethical Approval All procedures performed in studies involving human participants were following the ethical standards of the institutional and/or national research committee and with the 1964 Helsinki declaration and its later amendments or comparable ethical standards.

Informed Consent Informed consent was obtained from all individual participants included in the study.

Conflict of Interest The authors declare no competing interests.

\section{References}

Abdelrahman, M., Al-Adwan, D., \& Hasan, Y. (2021). Impact of social distancing on the mental health of parents and children in Qatar. International Journal of Mental Health and Addiction, 1-12 
Alpay, E., Kira, I., Shuwiekh, H., Ashby, J. S., Turkeli, A., \& Alhuwailah, A. (2021). The effects of COVID-19 continuous traumatic stress on mental health: The case of Syrian refugees in Turkey. Traumatology: A International Journal. Online first

Ano, G. G., \& Vasconcelles, E. B. (2005). Religious coping and psychological adjustment to stress: A meta-analysis. Journal of Clinical Psychology, 61(4), 461-480.

Banerjee, D. (2020). The impact of Covid-19 pandemic on elderly mental health. International Journal of Geriatric Psychiatry. Online first

Barbosa-Leiker, C., Kostick, M., Lei, M., McPherson, S., Roper, V., Hoekstra, T., \& Wright, B. (2013). Measurement invariance of the perceived stress scale and latent mean differences across gender and time. Stress and Health, 29(3), 253-260.

Barth, J., Schneider, S., \& Von Känel, R. (2010). Lack of social support in the etiology and the prognosis of coronary heart disease: A systematic review and meta-analysis. Psychosomatic Medicine, 72(3), 229-238.

Bazzoli, A., Probst, T. M., \& Lee, H. J. (2021). Economic stressors, COVID-19 attitudes, worry, and behaviors among US working adults: A mixture analysis. International Journal of Environmental Research and Public Health, 18(5), 2338.

Benson, P. L., Scales, P. C., \& Syvertsen, A. K. (2011). The contribution of the developmental assets framework to positive youth development theory and practice. In R. M. Lerner, J. V. Lerner, \& J. B. Benson (Eds.), Advances in Child Development and Behavior (pp. 197-230). Elsevier.

Bornet, M. A., Bernard, M., Jaques, C., Truchard, E. R., Borasio, G. D., \& Jox, R. J. (2020). Assessing the will to live: A scoping review. Journal of Pain and Symptom Management. Online first

Byrne, B. M. (2012). Choosing structural equation modeling computer software: Snapshots of LISREL, EQS, AMOS, and Mplus. In R. H. Hoyle (Ed.), Handbook of structural equation modeling (pp. 307-324). The Guilford Press.

Campbell-Sills, L., \& Stein, M. B. (2007). Psychometric analysis and refinement of the Connor-Davidson resilience scale (CD-RISC): Validation of a 10-item measure of resilience. Journal of Traumatic Stress, 20(6), 1019-1028.

Cénat, J. M., Blais-Rochette, C., Kokou-Kpolou, C. K., Noorishad, P. G., Mukunzi, J. N., McIntee, S. E., ... \& Labelle, P. (2020). Prevalence of symptoms of depression, anxiety, insomnia, posttraumatic stress disorder, and psychological distress among populations affected by the COVID-19 pandemic: A systematic review and meta-analysis. Psychiatry Research, 113599.

Cooke, J. E., Eirich, R., Racine, N., \& Madigan, S. (2020). Prevalence of posttraumatic and general psychological stress during COVID-19: A rapid review and meta-analysis. Psychiatry Research, 292, 113347.

Connor, K. M., \& Davidson, J. R. (2003). Development of a new resilience scale: The Connor-Davidson resilience scale (CD-RISC). Depression and Anxiety, 18(2), 76-82.

Darling Rasmussen, P., Storebø, O. J., Løkkeholt, T., Voss, L. G., Shmueli-Goetz, Y., Bojesen, A. B., ... \& Bilenberg, N. (2019). Attachment as a core feature of resilience: A systematic review and metaanalysis. Psychological Reports, 122(4), 1259-1296

De France, K., Hancock, G. R., Stack, D. M., Serbin, L. A., \& Hollenstein, T. (2021, May 24). The Mental health implications of COVID-19 for adolescents: Follow-up of a four-wave longitudinal study during the pandemic. American Psychologist. Advance online publication.

Djelantik, A. M. J., Bui, E., O’Connor, M., Rosner, R., Robinaugh, D. J., Simon, N. M., \& Boelen, P. (2021). Traumatic grief research and care in the aftermath of the COVID-19 pandemic. European Journal of Psychotraumatology, 12(1), 1957272.

Eisma, M. C., Boelen, P. A., \& Lenferink, L. I. (2020). Prolonged grief disorder following the Coronavirus (COVID-19) pandemic. Psychiatry Research, 288, 113031.

Erickson, J., El-Gabalawy, R., Palitsky, D., Patten, S., Mackenzie, C. S., Stein, M. B., \& Sareen, J. (2016). Educational attainment as a protective factor for psychiatric disorders: Findings from a nationally representative longitudinal study. Depression and Anxiety, 33(11), 1013-1022.

Eschenbeck, H., Kohlmann, C. W., \& Lohaus, A. (2007). Gender differences in coping strategies in children and adolescents. Journal of Individual Differences, 28(1), 18-26.

Färber, F., \& Rosendahl, J. (2018). The association between resilience and mental health in the somatically ill: A systematic review and meta-analysis. Deutsches Ärzteblatt International, 115(38), 621.

Fischer, P., Ai, A. L., Aydin, N., Frey, D., \& Haslam, S. A. (2010). The relationship between religious identity and preferred coping strategies: An examination of the relative importance of interpersonal 
and intrapersonal coping in Muslim and Christian faiths. Review of General Psychology, 14(4), 365-381.

Gao, J., Zheng, P., Jia, Y., Chen, H., Mao, Y., Chen, S., ... \& Dai, J. (2020). Mental health problems and social media exposure during COVID-19 outbreak. PLoS One, 15(4), e0231924.

Gloster, A. T., Lamnisos, D., Lubenko, J., Presti, G., Squatrito, V., Constantinou, M., ... \& Karekla, M. (2020). Impact of COVID-19 pandemic on mental health: An international study. PLoS ONE, 15(12). https://doi.org/10.1371/journal.pone.0244809

Hackney, C. H., \& Sanders, G. S. (2003). Religiosity and mental health: A meta-analysis of recent studies. Journal for the Scientific Study of Religion, 42(1), 43-55.

Haggard, P. (2017). Sense of agency in the human brain. Nature Reviews Neuroscience, 18(4), $196-207$.

Hair, J. F., Hult, G. T. M., Ringle, C. M., \& Sarstedt, M. (2017). A Primer on Partial Least Squares Structural Equation Modeling (PLS-SEM) (2nd ed.). Sage.

Holman, E. A., Thompson, R. R., Garfin, D. R., \& Silver, R. C. (2020). The unfolding COVID-19 pandemic: A probability-based, nationally representative study of mental health in the United States. Science Advances, 6(42), eabd5390.

Hu, T., Zhang, D., \& Wang, J. (2015). A meta-analysis of the trait resilience and mental health. Personality and Individual Differences, 76, 18-27.

Hutschnecker, A. A. (1951). The will to live. Cornerstone Library.

Ikizer, G., Karanci, A. N., Gul, E., \& Dilekler, I. (2021). Post-traumatic stress, growth, and depreciation during the COVID-19 pandemic: Evidence from Turkey. European Journal of Psychotraumatology, $12(1), 1872966$.

Inagaki, T. K. (2018). Neural mechanisms of the link between giving social support and health. Annals of the New York Academy of Sciences, 1428(1), 33-50.

Kira, I. (2019). Toward an integrative theory of self-identity and identity stressors and traumas and its mental health dynamic. Psychology, 10, 385-410.

Kira, I.A. (2021). Taxonomy of stressors and traumas: An update of the development-based trauma framework (DBTF): A life-course perspective on stress and trauma. Traumatology. Online First

Kira, I. \& Shuwiekh, H. (2021).Discrimination and mental health of christians in Egypt: Coping trajectories and perceived posttraumatic growth. Mental Health, Religion, and Culture. Online first

Kira, I., Templin, T., Lewandowski, L., Clifford, D., Wiencek, E., Hammad, A., Al-Haidar, A., \& Mohanesh, J. (2006). The effects of torture: Two community studies. Peace and Conflict: Journal of Peace Psychology, 12(3), 205-228.

Kira, I., Abou-Mediene, S., Ashby, J., Lewandowski, L., Mohanesh, J., \& Odenat, L. (2012). Post-traumatic growth inventory: Psychometric properties of the Arabic version in Palestinian adults. The International Journal of Educational and Psychological Assessment, 11(2), 120-137.

Kira, I., Abou-Mediene, S., Ashby, J., Odenat, L., Mohanesh, J., \& Alamia, H. (2013a). The dynamics of post-traumatic growth across different trauma types in a Palestinian sample. Journal of Loss and Trauma: International Perspectives on Stress \& Coping, 18, 120-139.

Kira, I. A., Ashby, J. S., Lewandowski, L., Alawneh, A. W. N., Mohanesh, J., \& Odenat, L. (2013b). Advances in continuous traumatic stress theory: Traumatogenic dynamics and consequences of intergroup conflict: The Palestinian adolescents' case. Psychology, 4, 396-409.

Kira, I., Alawneh, A., Boumediene, S., Lewandowski, L., \& Laddis, A. (2014a). Dynamics of oppression and coping from traumatology perspective: The example of Palestinian youth. Peace and Conflict: Journal of Peace Psychology, 20(4), 385-411.

Kira, I., Alawneh, A., Boumediene, S., Lewandowski, L., \& Laddis, A. (2014b). Dynamics of oppression and coping from traumatology perspective: The example of Palestinian youth. Peace and Conflict: Journal of Peace Psychology., 20(4), 385-411.

Kira, I., Lewandowski, L., Chiodo, L., \& Ibrahim, A. (2014c). Advances in systemic trauma theory: Traumatogenic dynamics and consequences of backlash as a multi-systemic trauma on Iraqi refugee muslim adolescents. Psychology, 5, 389-412.

Kira, I., Ashby, J. S., Omidy, A. Z., \& Lewandowski, L. (2015). Current, Continuous, and Cumulative Trauma-Focused Cognitive Behavior Therapy: A new model for trauma counseling. Journal of Mental Health Counseling, 37, 323-340.

Kira, I., Shuwiekh, H., Al-Huwailah, A. H., Zidan, T., \& Bujold-Bugeaud, M. (2019). Measuring interfaith spirituality: Initial validation and psychometrics. Psychology of Religion and Spirituality. Advance online publication.https://doi.org/10.1037/rel0000242 
Kira, I. A., Özcan, N. A., Shuwiekh, H., Kucharska, J., Al-Huwailah, A. \& Kanaan, A. (2020a). The compelling dynamics of "will to exist, live and survive" on effecting PTG upon exposure to adversities: Is it mediated, in part, by emotional regulation, resilience, and spirituality. Traumatology: An International Journal. Online first.

Kira, I., Shuwiekh, H., Alhuwailah, A., Ashby, J. S., Sous, M., Baali, S., Azdaou, C., Oliemat, E. \& Hikmet, J. (2020b). The effects of COVID-19 and collective identity trauma (intersectional discrimination) on Social Status and Wellbeing. Traumatology. Online first.

Kira, I. A., Shuwiekh, H., Kucharska, J., Al-Huwailah, A. H., \& Moustafa, A. (2020c). "Will to Exist, Live and Survive" (WTELS): Measuring its role as master/metamotivator and in resisting oppression and related adversities. Peace and Conflict: Journal of Peace Psychology, 26(1), 47-61.

Kira, I., Shuwiekh, H., Rice, K., Ashby, J. S., Elwakeel, S., Fahmy, M., Alhuwailah, A., Baali, S.,Azdaou, C., Oliemat, E. \& Jamil, H. (2020d). Measuring COVID-19 as traumatic stress: Initial psychometrics and validation. Journal of Loss and Trauma: International Perspectives on Stress \& Coping. Online first.

Kira, I., Alpay, E. H., Ayna, W. E., Shuwiekh, H., Ashby, J. S., Turkeli, A. (2021a). The effects of COVID-19 continuous traumatic stressors on mental health and cognitive functioning: A case example from Turkey. Current Psychology. Online first.

Kira, I., Alpay, E. H., Turkeli, A., Shuwiekh, H., Ashby, J.S., \& Alhuwailah, A. (2021b). The effects of COVID-19 traumatic stress on Executive functions: The case of Syrian refugees in Turkey. Journal of Loss and Trauma: International Perspectives on Stress \& Coping. Advanced online Publication.

Kira, I. (2021b). The development-based taxonomy of stressors and traumas: An initial empirical validation. Psychology, 12, 1575-1614.

Kira, I., Ayna, Y. E., Shuwiekh, H. A. M., \& Ashby, J. S. (2021c). The association of WTELS as a master motivator with higher executive functioning and better mental health. Current Psychology.

Kira, I., Özcan, N., Shuwiekh, H., Kucharska, J., Al-Huwailah, A. \& Bujold-Bugeaud, M. (2021d). Mental health dynamics of interfaith spirituality in believers and non-believers: The two circuit pathways model of coping with adversities: Interfaith Spirituality and Will-to Exist, Live and Survive. Psychology

Kira, I. A., Shuwiekh, H., Ashby, J. S., Rice, K. \& Alhuwailah, A. (2021e). Measuring COVID-19 Stressors and their impact: The second-order factor model and its four first-order factors: infection fears, economic, grief, and lockdown stressors. Journal of Loss and Trauma: International Perspectives on Stress \& Coping. Online first.

Kira, I., Shuwiekh, H., Rice, K., Ashby, J.S., Alhuwailah, A., Sous, M., Baali, S., Azdaou, C., Oliemat, E. \& Jamil, H. (2021f). Coping with COVID-19 continuous complex stressors: The "Will-to-ExistLive, and Survive" and perfectionistic striving. Traumatology: An International Journal.

Kroenke, C. H., Kubzansky, L. D., Schernhammer, E. S., Holmes, M. D., \& Kawachi, I. (2006). Social networks, social support, and survival after breast cancer diagnosis. Journal of Clinical Oncology, 24(7), 1105-1111.

Le Couteur, D. G., Anderson, R. M., \& Newman, A. B. (2020). COVID-19 is a disease of older people. Journals of Gerontology. Series a, Biological Sciences and Medical Sciences, 75, e119-e120.

Lorant, V., Deliège, D., Eaton, W., Robert, A., Philippot, P., \& Ansseau, M. (2003). Socioeconomic inequalities in depression: A meta-analysis. American Journal of Epidemiology, 157(2), 98-112.

Luo, M., Guo, L., Yu, M., \& Wang, H. (2020). The psychological and mental impact of coronavirus disease 2019 (COVID-19) on medical staff and general public-A systematic review and meta-analysis. Psychiatry Research, 113190.

Marvaldi, M., Mallet, J., Dubertret, C., Moro, M. R., \& Guessoum, S. B. (2021). Anxiety, depression, trauma-related, and sleep disorders among healthcare workers during the COVID-19 pandemic: A systematic review and meta-analysis. Neuroscience \& Biobehavioral Reviews, 126, 252-264.

McGinty, E. E., Presskreischer, R., Anderson, K. E., Han, H., \& Barry, C. L. (2020). Psychological distress and COVID-19-related stressors reported in a longitudinal cohort of US adults in April and July 2020. JAMA, 324(24), 2555-2557.

Miyazaki, T., Ishikawa, T., Iimori, H., Miki, A., Wenner, M., Fukunishi, I., \& Kawamura, N. (2003). Relationship between perceived social support and immune function. Stress and Health: Journal of the International Society for the Investigation of Stress, 19(1), 3-7. 
Nuttman-Shwartz, O., \& Green, O. (2020). Resilience truths: Trauma resilience workers' points of view toward resilience in continuous traumatic situations. International Journal of Stress Management. Advance online publication.

Oshio, A., Taku, K., Hirano, M., \& Saeed, G. (2018). Resilience and Big Five personality traits: A metaanalysis. Personality and Individual Differences, 127, 54-60.

Peverill, M., Dirks, M. A., Narvaja, T., Herts, K. L., Comer, J. S., \& McLaughlin, K. A. (2020). Socioeconomic status and child psychopathology in the United States: A meta-analysis of population-based studies. Clinical Psychology Review, 101933.

Pierce, M., McManus, S., Hope, H., Hotopf, M., Ford, T., Hatch, S. L., ... \& Abel, K. M. (2021). Mental health responses to the COVID-19 pandemic: A latent class trajectory analysis using longitudinal UK data. The Lancet Psychiatry. Online first.

Piquero, A. R., Jennings, W. G., Jemison, E., Kaukinen, C., \& Knaul, F. M. (2021). Evidence from a systematic review and meta-analysis: Domestic Violence during the COVID-19 Pandemic. Journal of Criminal Justice, 101806.

Prati, G., \& Mancini, A. D. (2021). The psychological impact of COVID-19 pandemic lockdowns: A review and meta-analysis of longitudinal studies and natural experiments. Psychological Medicine, 1-11.

Prime, H., Wade, M., \& Browne, D. T. (2020). Risk and resilience in family well-being during the COVID19 pandemic. American Psychologist, 75(5), 631.

Rogers, J. P., Chesney, E., Oliver, D., Pollak, T. A., McGuire, P., Fusar-Poli, P., ... \& David, A. S. (2020). Psychiatric and neuropsychiatric presentations associated with severe coronavirus infections: A systematic review and meta-analysis with comparison to the COVID-19 pandemic. The Lancet Psychiatry, 7(7), 611-627

Saddik, B., Hussein, A., Albanna, A., Elbarazi, I., Al-Shujairi, A., Temsah, M. H., ... \& Halwani, R. (2021). The psychological impact of the COVID-19 pandemic on adults and children in the United Arab Emirates: A nationwide cross-sectional study. BMC Psychiatry, 21(1), 1-18

Salari, N., Hosseinian-Far, A., Jalali, R., Vaisi-Raygani, A., Rasoulpoor, S., Mohammadi, M., ... \& KhalediPaveh, B. (2020). Prevalence of stress, anxiety, depression among the general population during the COVID-19 pandemic: A systematic review and meta-analysis. Globalization and Health, 16(1), 1-11

Salehi, M., Amanat, M., Mohammadi, M., Salmanian, M., Rezaei, N., Saghazadeh, A., \& Garakani, A. (2021). The prevalence of post-traumatic stress disorder-related symptoms in Coronavirus outbreaks: A systematic review and meta-analysis. Journal of affective disorders. Online first.

Scali, J., Gandubert, C., Ritchie, K., Soulier, M., Ancelin, M. L., \& Chaudieu, I. (2012). Measuring resilience in adult women using the 10-items Connor-Davidson Resilience Scale (CD-RISC). Role of trauma exposure and anxiety disorders. PLOS One, 7(6), e39879.

Shanmugasegaram, S., Russell, K. L., Kovacs, A. H., Stewart, D. E., \& Grace, S. L. (2012). Gender and sex differences in prevalence of major depression in coronary artery disease patients: A meta-analysis. Maturitas, 73(4), 305-311.

Sherbourne, C. D., \& Stewart, A. L. (1991). The MOS social support survey. Social Science \& Medicine, 32(6), 705-714.

Shuwiekh, H., Kira, I., Fahmy, M., Ashby, J. S., Alhuwailah, A., Baali, S., Azdaou, C., Oliemat, E., Jamil, H. (2020). The differential mental health impact of COVID-19 in Arab Countries. Current Psychology. Online first.

Şimşir, Z., Koç, H., Seki, T., \& Griffiths, M. D. (2021). The relationship between fear of COVID-19 and mental health problems: A meta-analysis. Death Studies, 1-9.

Southwick, S. M., Bonanno, G. A., Masten, A. S., Panter-Brick, C., \& Yehuda, R. (2014). Resilience definitions, theory, and challenges: Interdisciplinary perspectives. European Journal of Psychotraumatology, 5(1), 25338.

Tedeschi, R. G., \& Calhoun, L. G. (1996). The Posttraumatic Growth Inventory: Measuring the positive legacy of trauma. Journal of Traumatic Stress, 9(3), 455-471.

Tuite, A. R., Ng, V., Rees, E., Fisman, D.,Wilder-Smith, A., Khan, K., \& Bogoch, I. I. (2020). Estimation of the COVID-19 burden in Egypt through exported case detection. The Lancet Infectious Diseases

Weston, R., \& Gore, P. A., Jr. (2006). A brief guide to structural equation modeling. The Counseling Psychologist, 34(5), 719-751.

Yu, Z., Razzaq, A., Rehman, A., Shah, A., Jameel, K., \& Mor, R. S. (2021). Disruption in global supply chain and socio-economic shocks: A lesson from COVID-19 for sustainable production and consumption. Operations Management Research, 1-16. 
Yuan, K., Gong, Y. M., Liu, L., Sun, Y. K., Tian, S. S., Wang, Y. J., ... \& Lu, L. (2021). Prevalence of posttraumatic stress disorder after infectious disease pandemics in the twenty-first century, including COVID-19: A meta-analysis and systematic review. Molecular Psychiatry, 1-17.

Vally, Z., Cody, B. L., Alsheraifi, S. N., \& Albloshi, M. A. (2018). A comparative description of perceived stress and coping strategies among psychology and non-psychology students in the United Arab Emirates. Perspectives in Psychiatric Care, 54(4), 539-546.

Verdolini, N., Amoretti, S., Montejo, L., García-Rizo, C., Hogg, B., Mezquida, G., ... \& Solé, B. (2021). Resilience and mental health during the COVID-19 pandemic. Journal of Affective Disorders, 283, $156-164$

Volk, A. A., Brazil, K. J., Franklin-Luther, P., Dane, A. V., \& Vaillancourt, T. (2021). The influence of demographics and personality on COVID-19 coping in young adults. Personality and Individual Differences, 168, 110398.

Vera, E., Yoon, E., Chander, N., Kim, D., Liu, H., Kolas, D., ... \& Ahmad Mustaffa, E. (2020). A metaanalysis of support variables and well-being in ethnic minority populations. Journal of Applied Social Psychology, 50(11), 660-675.

Publisher's Note Springer Nature remains neutral with regard to jurisdictional claims in published maps and institutional affiliations.

\section{Authors and Affiliations}

\section{Ibrahim A. Kira ${ }^{1,2} \cdot$ Hanaa A. M. Shuwiekh ${ }^{3}$. Shereen Abd Elwahab Ahmed ${ }^{3}$. Eman Ezzat Ebada ${ }^{3}$. Shireen Farouk Tantawy ${ }^{3} \cdot$ Nevein Nirouz Waheep $^{3}$. Jeffrey S. Ashby ${ }^{4}$}

Hanaa A. M. Shuwiekh

has11@fayoum.edu.eg

Shereen Abd Elwahab Ahmed

Saa13@fayoum.edu.eg

Eman Ezzat Ebada

Eee11@fayoum.edu.eg

Shireen Farouk Tantawy

Sfm00@fayoum.edu.eg

Nevein Nirouz Waheep

Nnw11@fayoum.edu.eg

Jeffrey S. Ashby

jashby2@gsu.edu

1 Center for Cumulative Trauma Studies, 4906 Woodhurst Way, Stone Mountain, GA 30088, USA

2 Affiliate of Center for Stress, Trauma and Resiliency, Georgia State University, Atlanta, GA, USA

3 Fayoum University, Faiyum, Egypt

4 Stress, Trauma and Resiliency, Georgia State University, Atlanta, GA, USA 